\title{
Tamoxifen/Ribociclib Regimen
}

National Cancer Institute

\section{Source}

National Cancer Institute. Tamoxifen/Ribociclib Regimen. NCI Thesaurus. Code C156375.

A chemotherapy regimen consisting of tamoxifen and ribociclib that may be used in the treatment of hormone receptor (HR)-positive advanced or metastatic breast cancer. 